\title{
PERBANDINGAN PERTUMBUHAN TANAMAN PORANG (Amorphophallus muelleri) AGROFORESTRY DAN MONOKULTUR PADA KELOMPOK TANI SARI BUNGA KAYU KABUPATEN LUWU TIMUR
}

\section{(Comparison of Porang (Amorphophallus muelleri) Agroforestry and Monoculture Growth on the Sari Bunga Kayu Farmer's Group, East Luwu Regency)}

\author{
Maria $^{1}$, Srida Mitra Ayu ${ }^{1}$, Lani $^{1}$. \\ Program Studi Kehutanan, Fakultas Kehutanan, Universitas Andi Djemma Palopo \\ E-mail:mariaforestry@gmail.com
}

\begin{abstract}
This study aims to determine the comparison of the growth of porang plants managed by agroforestry and monoculture. This research took place from April to May 2021. The data was collected in the form of primary data and secondary data. This study was a completely randomized design consisting of 2 treatments and eight replications on agroforestry and monoculture land so that there were 32 experimental units. Treatment using media M1=Soil $(100 \%)$ and $M 2=$ Soil + husk charcoal. Furthermore, analysis of variance (Manova) was carried out; the analysis of variance showed that on agroforestry land, the treatment had a very significant effect on stem height and substantially impacted the number of leaves. In contrast, in monoculture, the treatment significantly impacted stem height and had no significant effect on the number of leaves. Based on the results of the research, the best porang plant growth was found on agroforestry land that used soil + husk charcoal in terms of plant height parameters and a number of leaves with an average plant height value of $27.2 \mathrm{~cm}$ and gave the best results on the number of leaves with an average value of 3 strands. At the same time, the lowest porang plant growth was on monoculture land with an average plant height value of $19 \mathrm{~cm}$ and the number of leaves with an average value of 1 strand.
\end{abstract}

Keywords: Growth Comparison, Agroforestry, Monoculture, Porang

\section{ABSTRAK}

Penelitian ini bertujuan untuk mengetahui perbandingan pertumbuhan tanaman porang yang dikelola secara agroforestry dan monokultur. Penelitian ini berlangsung pada bulan April sampai Mei 2021. Data yang dikumpulkan berupa data primer dan data sekunder. Metode yang digunakan dalam penelitian ini yaitu rancangan acak lengkap yang terdiri dari 2 perlakuan dan 8 ulangan pada lahan agroforestry dan monokultur sehingga terdapat 32 unit percobaan. Perlakuan menggunakan media M1=Tanah (100\%) dan M2=Tanah + Arang sekam. Selanjutnya dilakukan analisis sidik ragam (Manova), hasil analisis sidik ragam menunjukkan pada lahan agroforestry perlakuan berpengaruh sangat nyata terhadap tinggi batang dan berpengaruh nyata terhadap jumlah daun, sedangkan pada lahan monokultur perlakuan berpengaruh nyata terhadap tinggi batang dan tidak berpengaruh nyata terhadap jumlah daun. Berdasarkan hasil penelitian pertumbuhan tanaman porang terbaik terdapat pada lahan agroforestry yang menggunakan media tanah + arang sekam ditinjau dari parameter tinggi tanaman dan jumlah daun dengan nilai rata-rata tinggi tanaman yaitu $27.2 \mathrm{~cm}$ dan memberikan hasil terbaik pada jumlah daun dengan nilai rata-rata 3 helai Sedangkan pertumbuhan tanaman porang terendah terdapat pada lahan monokultur dengan nilai rata-rata tinggi tanaman yaitu 19 $\mathrm{cm}$ dan jumlah daun dengan nilai rata-rata 1 helai.

Kata Kunci : Perbandingan Pertumbuhan, Agroforestry, Monokultur, Porang 


\section{PENDAHULUAN}

Porang dalam Permenhut No P.35/Menhut/2007 tentang Hasil Hutan Bukan Kayu (HHBK) termasuk ke dalam jenis HHBK berupa umbi-umbian penghasil pati yang memiliki banyak kegunaan. Tanaman porang dapat dibudidayakan secara monokultur maupun agroforestry dengan porang sebagai komoditas utama (Mahrizal, 2013). Agroforestry adalah sistem penggunaan lahan (usaha tani) yang mengkombinasikan pepohonan dengan tanaman pertanian untuk meningkatkan keuntungan baik secara ekonomis maupun lingkungan. Sedangkan monokultur adalah salah satu cara budidaya di lahan pertanian degan menanam satu jenis tanaman pada satu areal.

Provinsi Sulawesi Selatan merupakan salah satu daerah produksi porang di kawasan selatan Indonesia. Setiap tahunnya, kebutuhan ekspor porang mencapai 750 ton untuk memenuhi perusahaan-perusahaan besar dunia, seperti Jepang dan Cina. Badan Karantina Pertanian menyebutkan ekspor porang pada tahun 2018 tercatat sebanyak 254 ton dengan nilai ekspor yang mencapai Rp 11,31 miliar ke Negara Jepang, Tiongkok, Vietnam, Australia. Kelompok Tani Sari Bunga Kayu Desa Beringin Jaya merupakan kelompok tani yang membudidayakan tanaman porang dengan sistem agroforestry dan monokultur. Petani beranggapan bahwa pengelolaan porang secara monokultur dapat memberikan hasil yang tinggi, sehingga banyak petani yang menebang pohon pelindung didalam lahan tanaman porang, padahal porang membutuhkan pelindung dalam jumlah yang sesuai untuk pertumbuhannya. Sementara hasil penelitian Mutiarasani (2008) menunjukkan bahwa sistem agroforestry tanaman porang yang dibudidayakan di Jawa Timur memiliki naungan yang ideal dengan kerapatan $40 \%$, dimana semakin rapat naungan maka pertumbuhan porang semakin baik. Berdasarkan uraian di atas maka perlu dilakukan penelitian untuk membandingkan pertumbuhan tanaman porang dengan sistem agroforestry dan monokultur.

Tujuan penelitian ini adalah untuk mengetahui Perbandingan Pertumbuhan Tanaman Porang yang di Kelola secara Agroforestry dan Monokultur pada Kelompok Tani Sari Bunga Kayu Kabupaten Luwu Timur. Penelitian ini berguna bagi petani porang dalam menerapkan budidaya terutama yang berkaitan dengan pertumbuhan tanaman porang yang dikelola seacara agroforestry dan monokultur yang berdampak terhadap keberlanjutan prodduktivitas tanaman porang.

\section{METODE PENELITIAN}

Penelitian ini dilaksanakan pada bulan April sampai Mei 2021 di Desa Beringin Jaya, Kecamatan Tomoni, Kabupaten Luwu Timur, Provinsi Sulawesi Selatan.

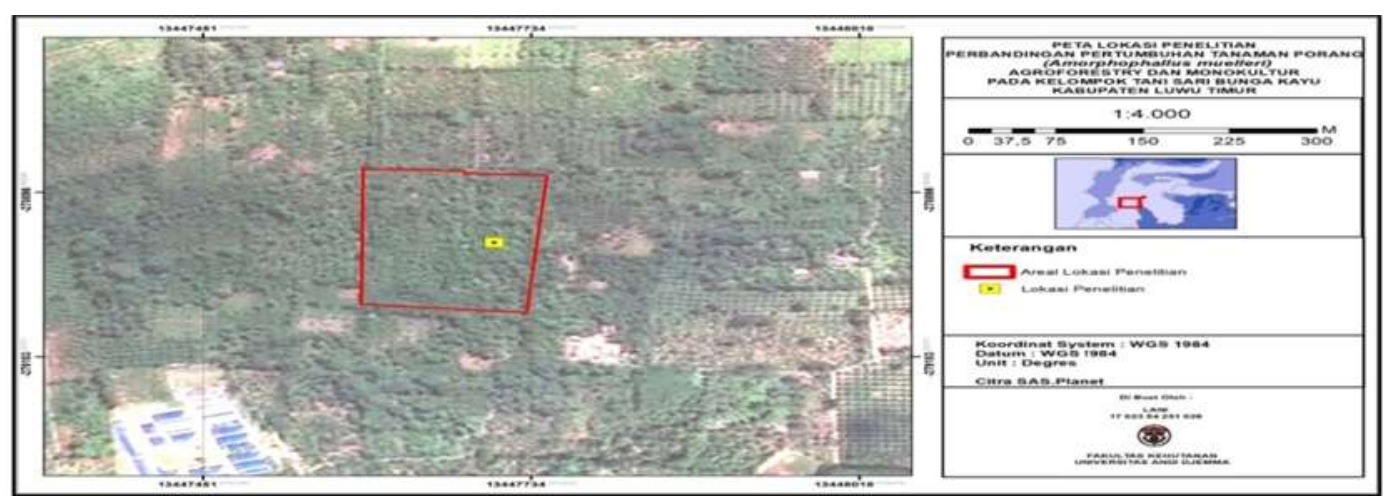

Gambar 1. Lokasi Penelitian 
Alat yang digunakan dalam penelitian ini yaitu penggaris, alat tulis, kamera, cangkul, roll meter, kantong plastik, timbagan digital, tally sheet, parang, gelas ukur dan semprot. Bahan yang digunakan yaitu bibit porang (siap tanam), tanah dan arang sekam, pupuk cair, papan penelitian, air, lux meter, thermometer, dan ph tester.

Jenis dan sumber data yang digunakan dalam penelitian ini terdiri atas dua yaitu data primer dan data sekunder. Data primer dalam penelitian ini adalah pengujkuran tinggi tanaman, jumlah daun, laju pertumbuhan dan persentase tumbuh masingmasing pada lahan agroforestry dan monokultur. Data sekunder yang dikumpulkan meliputi keadaan umum lokasi penelitian meliputi kondisi fisik lingkungan dan data dari literatur atau refrensi serta instansi-instansii terkait dengan penelitian.

Penelitian ini menggunakan metode Rancangan Acak Lengkap (RAL) menggunakan media tumbuh terhadap pertumbuhan tanaman porang :

M1 : Tanah (100\%)

M2 : Tanah + Arang Sekam

Pada lahan monokultur maupun agroforestry masing-masing perlakuan diulang sebanyak 8 kali sehingga terdapat 16 tanaman pada masing-masing lahan. Dari keseluruhan perlakuan diperoleh 32 unit percobaan.

Prosedur pengambilan data dimulai dengan persiapan lahan dengan cara lahan dibersihkan terlebih dahulu dengan menggunakan parang. Setelah lahan bersih dilanjutkan dengan menggemburkan tanah dengan menggunakan cangkul. Persiapan lahan dilakukan satu hari sebelum tanam. Persiapan lahan sebagai tempat penelitian pada lahan agroforestry yaitu mengukur areal yang diperlukan dengan ukuran lebar lahan $5 \mathrm{~m}$ dan monokultur $3 \mathrm{~m}$, panjang lahan $14 \mathrm{~m}$ dan monokultur $5.5 \mathrm{~m}$, jarak tanam $1.5 \mathrm{~m}$ dan monokultur $7 \mathrm{~cm}$, dengan lubang tanam sekitar $10 \mathrm{~cm}$, lebar guludan sekitar $20 \mathrm{~cm}$, serta jarak antar guludan sekitar $4.6 \mathrm{~m}$ dan monokultur $2.6 \mathrm{~m}$. Jarak antara lahan agroforestry dan monokultur adalah sekitar $8 \mathrm{~m}$. Pada sistem agroforestry petani menanami jenis tanaman pelindung tanaman hutan (kayu) berupa tegakan uru (Elmerrellia ovalis), jati putih (Gmelina arborea), dan pohon kelapa umur pohon berkisar sekitar 8-10 tahun. Serta pohon nangka umur pohon berkisar 2 tahun.

Persiapan Bibit porang diperoleh dari Kelompok Tani Sari Bunga Kayu sebanyak 32 bibit yang telah disemaikan selama 2 sampai 3 bulan. Bibit yang siap di tanam yaitu bibit yang telah mencapai ketinggian $20 \mathrm{~cm}$.

Kegiatan Penanaman dilakukan dengan cara memasukkan akarnya ke dalam lubang tanah, kemudian menutupnya dengan tanah. Pemindahan bibit haruslah hati-hati agar akarnya tetap utuh. Setiap lubang tanam di isi satu bibit. Media tanam arang sekam diukur menggunakan timbangan digital dengan berat 50 gram satu lubang tanam. Selanjutnya media tanam disiram dengan air. Kemudian memasang papan penelitian pada media tanam tanah dan arang sekam. Benih yang dipilih adalah benih yang seragam dan sehat atau bebas jamur. Pada saat satu minggu setelah penanaman dilakukan pemupukan dasar dengan pupuk cair bioorganik. Adapun cara pengaplikasiannya yaitu larutkan $20 \mathrm{ml}$ pupuk cair pada 1 liter air (1:50). Kemudian semprotkan pada bagian perakaran tanaman, penyemprotan dilakukan pada sore hari. Penyiangan di lakukan bersamaan dengan penggemburan tanah pada lahan tanam serta membersikan gulma yang ada disekitar tanaman dengan mengunakan tangan atau aret sebagai alat bantu dalam proses penyiangan. Di awal masa tanam penyiraman di lakukan 1-2 kali sehari,berikutnya di kurangi menjadi 2-3 kali seminggu tergantung cuaca serta kondisi tanah tidak boleh kekeringan atau tergenang air, pengamatan dilakukan setiap 1 minggu 1 kali. 


\section{Parameter Pengamatan}

1. Parameter Pertumbuhan Tanaman Porang yaitu tinggi tanaman, jumlah daun, laju pertumbuhan tanaman dan persentase tumbuh.

2. Data Lingkungan yaitu intensitas cahaya matahari, suhu dan kelembaban tanah, curah hujan dan ketinggian dari permukaan laut.

\section{Analisis Data}

Tinggi Batang

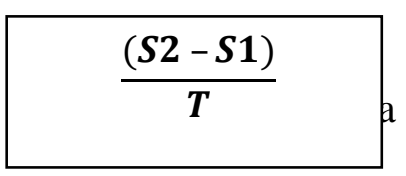

Dimana :

$$
\text { S1 }
$$

Pengukuran kedua

antara kedua pengukuran

$$
\text { T : Jarak }
$$

\section{Jumlah Daun}

\begin{tabular}{|c|c|c|}
\hline$\frac{(\boldsymbol{L} 2-\boldsymbol{L 1})}{\boldsymbol{T}}$ & Dimana : \\
& L1 $:$ \\
pertama & aat pengukuran
\end{tabular}

$$
\text { L2 : }
$$

Jumlah daun saat ppengukuran kedua

$$
\mathrm{T} \text { : Jarak }
$$

hari antara kedua pengukuran

\section{Laju Pertumbuhan}

$$
\text { pert. } \frac{\boldsymbol{L P T}=\frac{\boldsymbol{h n}-\boldsymbol{h o}}{\boldsymbol{\Sigma} \boldsymbol{n}}}{\text { tanaman hari ke-n }}
$$

Dimana :

$$
\text { LPT : Laju }
$$

hn : Tinggi

ho : Tinggi

tanaman hari awal pengukuran

Jumlah hari pengamatan

\section{Persentase Tumbuh}

$$
P i=\frac{n i}{n} \times 100 \%
$$

Dimana :

$\mathrm{Pi}$ : Persen uh tanaman

ni : Jumlah

tanama

n hidup

di

lapanga

$\mathrm{n}$ hasil

sensus

n : Jumlah

tanama

n yang

seharus

nya ada

(sesuai

jarak

tanam)

Pengujian sidik ragam dilakukan dengan MANOVA dan data diolah menggunakan aplikasi SPSS versi 20.

Hipotesis :

- $\operatorname{Sig}<0.05=$ Tolak H0, terima H1 artinya ada perbedaan antara perlakuan yang diberikan.

- Sig > $0.05=$ Terima H0 artinya tidak ada perbedaan antar perlakuan.

\section{HASIL DAN PEMBAHASAN}

\section{Kondisi Lingkungan yang Mempengaruhi} Pertumbuhan Tanaman Porang

Berdasarkan rata-rata pengukuran data lingkungan yang diamati dapat dilihat pada Tabel 1 .

Tabel 1. Data Lingkungan pada Lahan Agroforestry dan Monokultur

\begin{tabular}{ccc}
\hline \multirow{2}{*}{ Faktor Lingkungan } & \multicolumn{2}{c}{ Rata-rata } \\
\cline { 2 - 3 } Intensitas Cahaya Matahari & Agroforestry & Monokultur \\
Kelembaban Tanah & 50 lux & 83.3 lux \\
Suhu Udara & $46 \%$ & $35 \%$ \\
Curah Hujan & $25^{\circ} \mathrm{C}$ & $36^{\circ} \mathrm{C}$ \\
Ketinggian Tempat & \multicolumn{2}{c}{$3.092 \mathrm{~mm} / \mathrm{tahun}$} \\
\hline
\end{tabular}


Porang tumbuh optimal pada suhu $25^{\circ} \mathrm{C}$ sampai $35^{\circ} \mathrm{C}$ dengan curah hujan sekitar 1.000-1.500 mm/tahun dan 300-500 $\mathrm{mm} /$ bulan (Sumarwoto, 2012). Porang mampu beradaptasi dengan baik dilingkungan dengan kondisi hangat dan lembab dan dapat tumbuh pada ketinggian 0 - $700 \mathrm{~m}$ dpl, namun tumbuh baik pada ketinggian $100-600 \mathrm{~m}$ dpl. Porang tidak tahan terhadap intensitas cahaya tinggi dan membutuhkan naungan antara 50-60\% untuk pertumbuhan yang optimal.

\section{Tinggi Tanaman $(\mathbf{c m})$} Gambar 2.

Hasil pertumbuhan rata-rata tinggi tanaman porang dalam setiap minggu dilihat pada

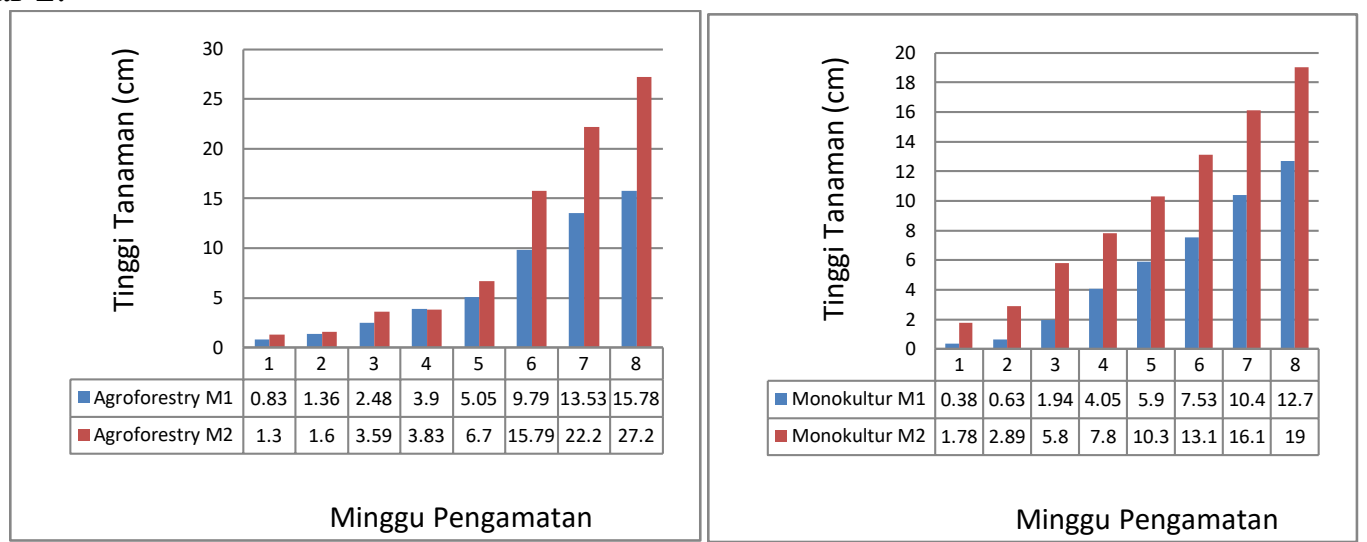

Gambar 2. Tinggi Tanaman Porang di Lahan Agroforestry dan Monokultur

Berdasarkan hasil tersebut dapat dikatakan bahwa pada perlakuan M1 maupun M2 ternyata pertumbuhan tinggi batang tanaman porang lebih baik di lahan agroforestry. Hal yang sama dinyatakan oleh Dijkstra (2010) bahwa sistem monokultur dapat berdampak negatif terhadap sifat tanah diantaranya menyebabkan defisiensi suatu jenis unsur hara karena kurangnya pengembalian residu tanaman ke dalam tanah. Hal lain yang mendukung kondisi tersebut adalah produksi yang dihasilkan oleh tanaman porang baik pada produksi umbi maupun produksi katak (bulbil). Produksi umbi diduga lebih besar dan berat terdapat pada lahan agroforestry dibanding lahan monokultur. Hal ini dikarenakan jarak tanam yang diterapkan berbeda, yaitu di lahan agroforestry $1.5 \mathrm{~m}$ dan monokultur $7 \mathrm{~cm}$ yang berarti bahwa di lahan monokultur tanaman porang terlalu rapat sehingga umbi tidak dapat berkembang dengan baik. Menurut Jata (2009) jarak tanam yang baik untuk hasil umbi tertinggi ditanam pada jarak $1 \mathrm{~m} \times 1 \mathrm{~m}$.

\section{Jumlah Daun (Helai)}

Hasil pertumbuhan rata-rata jumlah daun tanaman porang dalam setiap minggu dapat dilihat pada Gambar 3. 

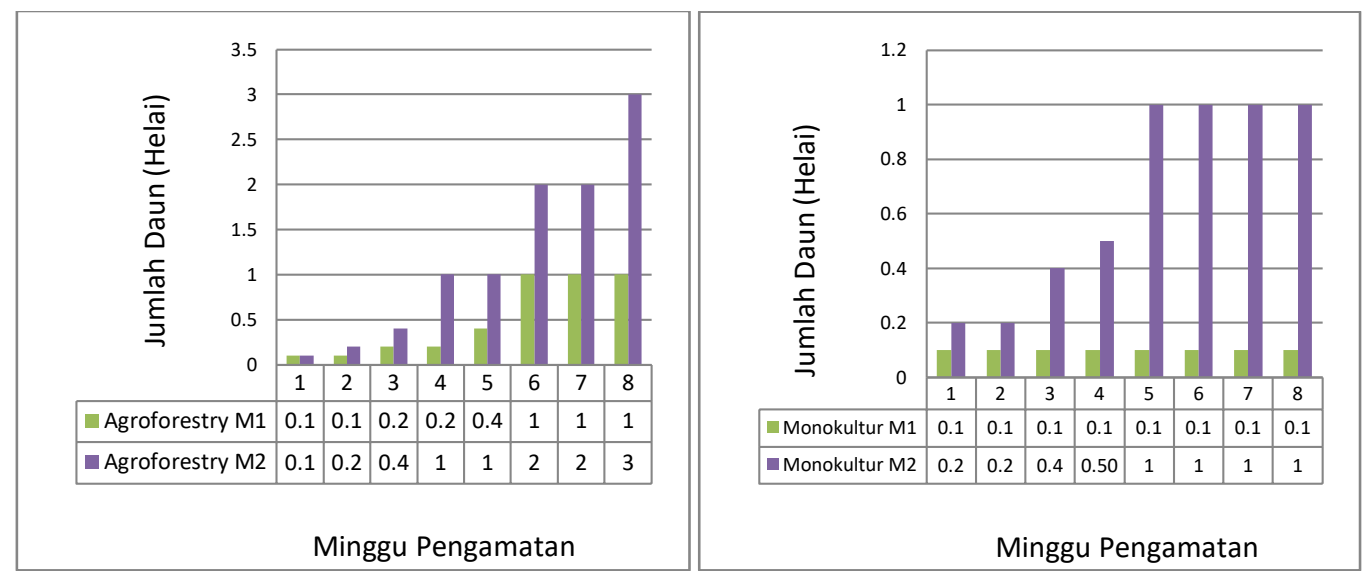

Gambar 3. Jumlah Daun Porang di Lahan Agroforestry dan Monokultur

Berdasarkan hasil tersebut dapat dikatakan bahwa pada perlakuan M1 maupun M2 ternyata pertumbuhan jumlah daun tanaman porang lebih baik di lahan agroforestry. Hal ini dipengaruhi oleh beberapa faktor lingkungan diantaranya suhu dan kelembaban tanah. Hal yang sama dinyatakan oleh Bambang Guritno (2006) bahwa pertumbuhan vegetatif pada tanaman dipengaruhi dari beberapa hal seperti faktor lingkungan, nutrisi, hormon dan genetika tanaman itu sendiri.

\section{Laju Pertumbuhan Tanaman (LPT) \\ Laju Pertumbuhan Tinggi Batang dan Jumlah Daun}

Berdasarkan laju pertumbuhan tinggi batang tanaman porang di lahan agroforestry dan monokultur dapat dilihat pada Tabel 2.

Tabel 2. Laju Tinggi Batang dan Jumlah Daun

\begin{tabular}{ccccccccc}
\hline $\begin{array}{c}\text { Minggu } \\
\text { Pengamatan }\end{array}$ & \multicolumn{9}{c}{ Laju Pertumbuhan Tanaman } \\
& \multicolumn{2}{c}{ Laju Tinggi Batang } & \multicolumn{7}{c}{ Laju Jumlah Daun } \\
& Agroforestry & \multicolumn{2}{c}{ Monokultur } & Agroforestry & Monokultur \\
\cline { 2 - 10 } & M1 & M2 & M1 & M2 & M1 & M2 & M1 & M2 \\
2 & 18.9 & 31.9 & 14.9 & 25.9 & 3 & 4 & 0 & 0 \\
3 & 16.0 & 20.9 & 13.0 & 14.9 & 2 & 4 & 0 & 1 \\
4 & 13.0 & 26.9 & 12.0 & 19.9 & 1 & 1 & 0 & 0 \\
5 & 16.9 & 19.6 & 12.0 & 16.9 & 0 & 1 & 0 & 2 \\
6 & 14.0 & 30.1 & 13.0 & 17.9 & 0 & 3 & 0 & 1 \\
7 & 17.9 & 27.4 & 12.9 & 17.0 & 0 & 2 & 0 & 1 \\
8 & 15.1 & 39.1 & 13.0 & 25.9 & 0 & 2 & 0 & 0 \\
\hline
\end{tabular}

Berdasarkan Tabel 2. dapat dilihat bahwa pada perlakuan M1 maupun M2 ternyata laju pertumbuhan tinggi tanaman porang lebih baik di lahan agroforestry. Hal yang sama dinyatakan oleh Senjaya (2018) bahwa pengolahan lahan dalam sistem agroforestry dapat meningkatkan pertumbuhan laju tinggi tanaman yang lebih besar dibandingkan dengan pengelolaan lahan secara monokultur, hal ini berkaitan dengan kondisi tempat tumbuh yang lebih mendukung untuk pertumbuhan tanaman. Hal lain yang mendukung kondisi tersebut adalah penambahan media tanam berupa arang sekam dianggap mampu memenuhi unsur hara pada tanaman. Menurut Rahmawati (2017) menyatakan bahwa tanaman akan tumbuh subur apabila unsur 
hara yang dibutuhkan tersedia dengan cukup terutama untuk pertumbuhan vegetatif seperti daun, batang dan akar.

Berdasarkan tabel 3. dapat dilihat bahwa bahwa pada perlakuan M1 maupun M2 ternyata laju pertumbuhan jumlah daun tanaman porang lebih baik di lahan agroforestry. Hal ini dikarenakan pada lahan agroforestry terdapat tegakan pohon yang menaungi tanaman porang sehingga membantu memelihara unsur hara pada tanaman. Hal yang sama dinyatakan oleh Sanchez (1997) bahwa tanaman pohonpohonan berperakaran dalam pada sistem agroforestry dapat membantu meningkatkan dan memelihara hara tanah, menekan erosi sekaligus mengkonversi air, disamping menghasilkan beberapa jenis produk yang memiliki ekonomi tinggi.

\section{Persentase Tumbuh (\%)}

Berdasarkan hasil pengamatan pada minggu kedelapan diperoleh persentase tumbuh yang sama (tumbuh semua) baik pada lahan agroforestry maupun lahan monokultur. Hal ini dikarenakan tanaman porang merupakan tanaman yang cepat tumbuh dilihat pada pertumbuhan akar yang cepat dalam waktu 7-14 hari kemudian tumbuh tunas baru. Media tanam juga mempengaruhi persentase tumbuh tanaman porang, dimana media tanam arang sekam menurut Septiani (2012) memiliki kemampuan menahan air yang tinggi dan porositas yang baik. Sifat ini menguntungkan jika digunakan sebagai media tanam karena mendukung perbaikan struktur tanah sehingga aerasi dan drainase menjadi lebih baik. Sedangkan untuk media berupa tanah persentase tumbuh tanaman juga baik namun tidak signifikan hal ini disebabkan karena pada media tanah unsur hara yang tersedia sangat terbatas. Menurut Sudewo (2005) mengatakan bahwa media tanam yang menyediakan air dan unsur hara terbatas akan mengakibatkan pertumbuhan tanaman tidak maksimal dan menyebabkan media tanam mudah kering dan tanaman akan cepat mati.

Tabel 3. Analisis Sidik Ragam Manova

\begin{tabular}{|c|c|c|c|c|c|c|c|}
\hline$\underline{\text { Pola }}$ & $\underline{\text { Sumber }}$ & $\begin{array}{l}\text { Variabel } \\
\text { Terikat } \\
\end{array}$ & $\underline{\text { Jumlah }}$ & $\underline{\mathrm{Db}}$ & $\frac{\text { Kuadrat }}{\text { Tengah }}$ & Fhitung & $\underline{\text { Sig }}$ \\
\hline \multirow{2}{*}{$\frac{\text { Agroforest }}{\text { ry }}$} & Perlakuan & Tinggi & 714.226 & $\underline{1}$ & 714.226 & $\underline{16.954}$ & .003 \\
\hline & & $\frac{\text { batang }}{\text { Jumlah }}$ & $\underline{14.063}$ & $\underline{1}$ & $\underline{14.063}$ & $\underline{18.103}$ & .004 \\
\hline \multirow{2}{*}{$\frac{\text { Monokultu }}{\underline{\mathrm{r}}}$} & $\underline{\text { Perlakuan }}$ & Tinggi & $\underline{156.876}$ & $\underline{1}$ & $\underline{156.876}$ & $\underline{19.457}$ & .004 \\
\hline & & $\frac{\text { Jumlah }}{\text { daun }}$ & $\underline{1.563}$ & $\underline{1}$ & $\underline{1.563}$ & $\underline{5.645}$ & .049 \\
\hline
\end{tabular}

Hasil analisis sidik ragam pada Tabel 3. dapat dilihat bahwa pada lahan agroforestry perlakuan berpengaruh sangat nyata terhadap pertumbuhan tinggi batang dan perlakuan berpengaruh nyata terhadap jumlah daun dengan nilai sig $<0.05$. Hal ini dikarenakan perlakuan media tanam dapat menjaga kelembaban daerah sekitar akar, menyediakan cukup udara, dan dapat menahan ketersediaan unsur hara. Hal ini sejalan dengan Pujisiswanto (2008), bahwa apabila unsur hara tersedia dalam jumlah mencukupi, mengakibatkan tinggi batang dan jumlah daun yang tumbuh pada suatu tanaman meningkat.

Hasil analisis sidik ragam pada lahan monokultur dapat dilihat bahwa perlakuan berpengaruh nyata terhadap pertumbuhan tinggi batang dengan nilai sig $<0.05$, dan perlakuan tidak memberikan pengaruh yang 
berbeda terhadap pertumbuhan jumlah daun dengan nilai sig di $>0.05$. Hal ini dikarenakan perlakuan mampu memberikan unsur hara yang baik, sehingga parameter pertumbuhan tinggi batang memperoleh hasil tertinggi, sedangkan untuk pertumbuhah jumlah daun ketersediaan unsur hara kurang sehingga sama sekali tidak mempengaruhi pertumbuhannya. Hal ini sejalan dengan Novizan (2005) bahwa ketersediaan unsur hara dapat diserap tanaman merupakan salah satu faktor yang dapat mempengaruhi tingkat pertumbuhan dan perkembangan tanaman, apabila tanaman kekurangan unsur hara tersebut maka akan menganggu kegiatan metabolisme tanaman sehingga proses pembentukan daun yang dalam hal ini sel-sel baru akan terhambat, dengan penambahan kompos kemungkinan tanaman akan menyerap hara lebih banyak sehingga sehingga pertumbuhan jumlah daun lebih baik.

\section{KESIMPULAN}

Pertumbuhan tanaman porang terbaik terdapat pada lahan agroforestry yang menggunakan media tanah + arang sekam ditinjau dari parameter tinggi tanaman dan jumlah daun dengan nilai rata-rata tinggi tanaman yaitu $27.2 \mathrm{~cm}$ dan memberikan hasil terbaik pada jumlah daun dengan nilai ratarata 3 helai. Sedangkan pertumbuhan tanaman porang terendah terdapat pada lahan monokultur dengan nilai rata-rata tinggi tanaman yaitu $19 \mathrm{~cm}$ dan jumlah daun dengan nilai rata-rata 1 helai.

\section{DAFTAR PUSTAKA}

Bambang Guritno dan S.M. Sitompul.2006. Analisis Pertumbuhan Tanaman. Fakultas Pertanian. Universitas Brawijaya Malang. Malang.

Dijkstra, F.A. and W. Cheng 2010. Interaction between soil and tree roots accelerate long-term soil karbon decomposition. Ecology

Letters, 10, 1046-1053.Diakses tanggal 15 Februari 2021.

Jata, S.K.,B. Sahoo, and M. Nedunchezhiyan. 2009.

Intercropping elepant foot yam in orchard crops. Orissa review October 2009. pp:82-84. Diakses tanggal 17 Februari 2021.

Novizan. 2005. Petunjuk Pemupukan yang Efektif. PT. Agromedia Pustaka. Jakarta.

Mahrizal. 2013. Keanekaragaman Jenis dan Komposisi Jenis Permudaan Alam Hutan Rawa Gambut Bekas Tebangan di Riau.Ethiopia.Biol.Fertil.Soil, 44, 53659.Diakses pada tanggal 15 Februari 2021.

Mutiarasani.2008.BudidayaPorang.http://mu tiarasani.blogspot.com/2008/04/budid aya-porang.html [diakses16 Februari 2021].

Permenhut No P./35/Menhut/2007 Tentang Hasil Hutan Bukan Kayu (HHBK).

Pujisiswanto, H dan D. Pangaribuan. 2008. Pengaruh Arang Sekam Terhadap Pertumbuhan Tomat. Prosiding Seminar Nasional Sains dan Teknologi II 2008. Universitas Lampung.

Rahmawati.Dkk. 2017.Aplikasi Kombinasi Kompos Kotoran Kambing Dengan Kompos Kotoran Ayam Dalam Meningkatkan Perumbuhan Dan Hasil Tanaman Kacang Tanah Varieta Gajah.

Sanchez, PA, Buresh, RJ, Leakey, RRB. 1997. Tress, soils, and food security. Philosophical transactions of the Royal Society, series A, 355. London.

Senjaya, N., Wijayanto, N., Wirnas, D. \& Achmad. 2018. Evaluasi Sistem Agroforestry Sengon Dengan Padi Gogo Terhadap Serangan Cendawan Rhizoctonia sp. J. Silvikultur Trop. 09, 120-126. 
Septiani, D. 2012. Pengaruh Pemberian Arang Sekam Padi Terhadap Pertumbuhan dan Hasil Tanaman Cabai Rawit (Capsicum frustescens). Politeknik Negeri Lampung. Lampung.

Sudewo, B. 2005. Basmi Penyakit dengan Sirih Merah. Agromedia Pustaka. Jakarta.

Sumarwoto. 2012. Beberapa sifat agronomi dan teknik budidaya porang (ilesiles). Ringkasan modul training for farmers.Program MHERE tahun 2012. Fakultas Kehutanan UGM. Yogyakarta. 